\title{
Cardiovascular System Findings Sequence Number
}

National Cancer Institute

\section{Source}

National Cancer Institute. Cardiovascular System Findings Sequence Number. NCI

Thesaurus. Code C124000.

An identifier that describes the relative position of cardiovascular system findings data within a series. 